\title{
Daily maximum and minimum temperature variation in Xiliugou basin for the period 1969-2010
}

\author{
Nan Zhang ${ }^{1}$, Hong Jiang ${ }^{2}$, Kui Huang ${ }^{1}$, Kai Du ${ }^{1}$ \\ 1. Yellow River Institute of Hydraulic Research, \\ No.45 of Shunhe Road, Zhengzhou 450003, China \\ E-mail: zhangnan19810202@126.com. Tel:13903852820 \\ 2. Yellow River Basin Water Resources Protection Bureau, \\ No.12 of Chengbei Road, Zhengzhou 450004, China)
}

\begin{abstract}
The paper presents an analysis of daily maximum, minimum and annual average diurnal temperature range. Three stations in XiLiuGou basin are analyzed to detect significant daily time trend from 1969 to 2010 . The homogeneity of the series is tested by means of the Standard Normal Homogeneity, the Buishand range and the Pettitt tests. The lack of randomness of the series, suggesting time trends, is also investigated by means of the Von Neumann ratio test. The results indicate that the empirical statistics departs from the $99 \%$ confidence level bands around 1986 years, most point of intersection before 1980s are in Tmax and Tmin. The most relevant period with negative Tmin trends is observed from November to March. Most positive temperature trends are general slightly more moderate from May to November for Tmax.
\end{abstract}

Keywords: XiLiuGou Basin, Tmax, Tmin, mDTR, Annual and seasonal scales, Trend analysis.

\section{INTRODUCTION}

Long-term climate variability is paramount for the estimation of its impact on human activities and for predicting the future climate[1]. Widely recognized and many time trend analyses at global, continental, regional and local scales can be cited. That estimates that the world is warming $0.6 \pm 0.2^{\circ} \mathrm{C}$ over 100 years. Temperature variations influence agriculture, architecture, transportation systems, power generation and its use.

Some scholars have studied the temperature time trend in the area of the Loess Plateau, Guo M P. et al [2] showed that the mean temperature in 1981-1990 was lower than in 1971-1980. Wang $\mathrm{R}$ A[3] concluded that maximum temperatures increased in the linearity trend, the climate changes of Pingliang gully region of Loess Plateau can be divided into three stages: before the 1970s the climate was colder, began to warm up in the 1980s, warm up more obviously in the 1990s.

In order to assess which locations and years are affected by temperature trends, this paper analyzed of time trends affecting calendar day temperatures, instead of annual, seasonal or monthly averaged temperatures for different locations in the study area. Owing to the daily scale of the analysis, it would be possible to detect what calendar day spells contribute to these patterns.

\section{DATA AND METHOD}

\section{A. Climatic data}

The Xiliugou basin located in middle of Yellow River,(Figure 1), which is one of the Ten-watered, it is a typically Monsoonal climate, the length is $106.5 \mathrm{~km}$, total area is $1356.3 \mathrm{~km} 2$, annual rainfall is $305.9 \mathrm{~mm}$, annual evaporation is $2200 \mathrm{~mm}$, annual temperature is $6.1{ }^{\circ} \mathrm{C}$, annual sediment concentration is $167 \mathrm{~kg} / \mathrm{m} 3$. The temporal and spatial (time, impact point, mild, duration, etc.) distribution of the basin's precipitation shows a strong randomness when it is affected by the impacts of atmospheric circulation. The ecological environment of Xiliugou basin is fragile, the soil is thinner, the soil erosivity is serious(Liu T. et al.). Soil and water erosivity, flood and sediment disasters caused by storm runoff are the main environmental problems. 


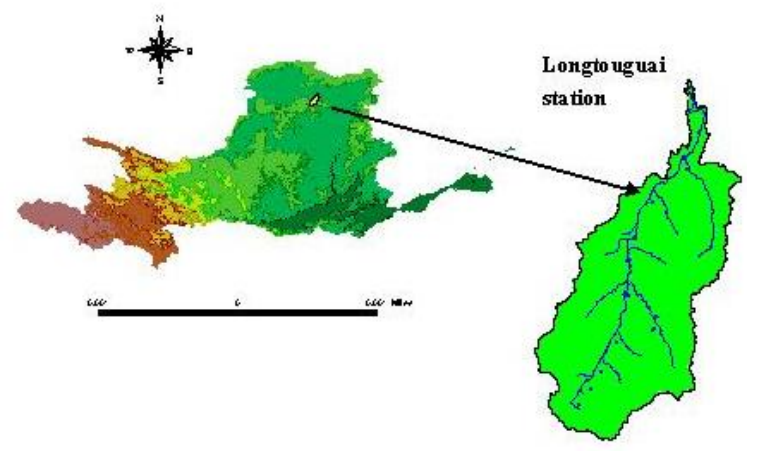

Fig 1. The map of the Xiliugou basin in the middle of the Yellow River

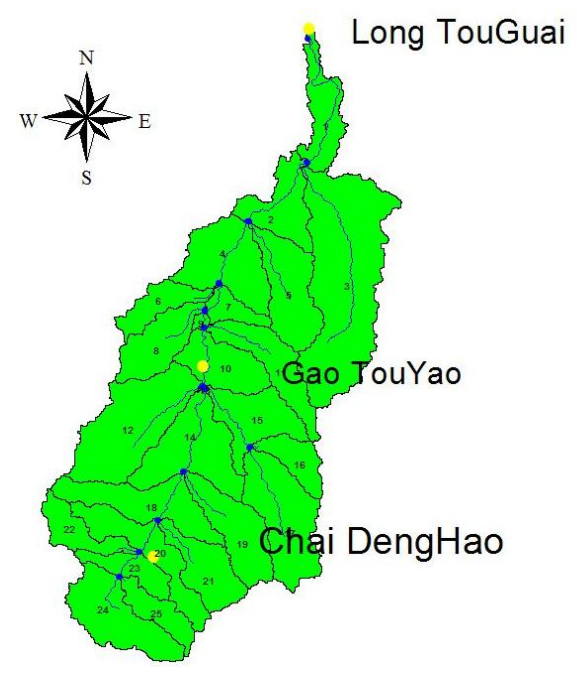

Fig 2. Weather station in the Xiliugou basin and it's vicinity

Table 1. Expected values of daily Tmax and Tmin and mDTR and standard deviations (SDmax, SDmin and SDDTR) for the 3 stations

\begin{tabular}{cccc}
\hline Code & $\mathrm{T}_{\max }\left({ }^{\circ} \mathrm{C}\right)$ & $\mathrm{SD}_{\max }\left({ }^{\circ} \mathrm{C}\right)$ & $\mathrm{T}_{\min }\left({ }^{\circ} \mathrm{C}\right)$ \\
\hline Long TouGuai & 37.3 & 11.96 & -31.5 \\
Gao TouYao & 38.7 & 13.36 & -33.8 \\
Chai DengHao & 38.9 & 12.81 & -31.2 \\
Code & $\mathrm{SD}_{\min }\left({ }^{\circ} \mathrm{C}\right)$ & $\mathrm{mDTR}\left({ }^{\circ} \mathrm{C}\right)$ & $\mathrm{SD}_{\mathrm{DTR}}\left({ }^{\circ} \mathrm{C}\right)$ \\
Long TouGuai & 12.01 & 13.60 & 0.77 \\
Gao TouYao & 13.22 & 13.48 & 1.02 \\
Chai DengHao & 12.20 & 12.65 & 0.77 \\
\hline
\end{tabular}

\section{B. Method}

In order to detect possible departures from homogeneity of temperature series, four tests are applied which are proved by Wijngaard JB [4]. The standard normal homogeneity test (SNHT) for single break [5], the Buishand range test (BRT) [6], the Pettitt test (PETT) [7], and the Von Neumann ratio test (VNRT) [8]. All of them suppose under the null hypothesis that the elements of the temperature series are independent and identically distributed. First three tests are capable of locating the year where a break is likely. The alternative hypothesis for the VNRT establishes a significance percentage for a lack of randomness of the series, which could be a sign of significant time trends. This paper using Mann-Kendall and Kendall-tau tests validate the field significance of every daily temperature trend.

\section{HOMOGENEITY TESTS AND RESUlTS}

In this study, the SNHT, the BRT and the PETT tests of homogeneity have been applied to annual average of daily $\mathrm{T}_{\text {max }}, \mathrm{T}_{\text {min }}$ and $\mathrm{T}_{\text {mean, }}$, the VNRT has been applied to residuals of monthly average of this temperature.

Table 2 lists the years for which a break is detected in each series by the first three tests. Bold characters indicated the breaking year finally assumed. It is worth mentioning that there is often an agreement in the breaking year detected by the three tests. When two out of three tests detect the same year, this is assumed as the breaking year.

A common breaking year, 1986, is detected by the three tests for monthly $\mathrm{T}_{\max }, \mathrm{T}_{\min }$ and $\mathrm{T}_{\text {mean }}$ of three stations, with a sharp temperature change of approximately $2.5^{\circ} \mathrm{C}$ in Long TouGuai station. For monthly $\mathrm{T}_{\max }$ of Gao TouYao station, the common breaking year is 1996 and the temperature change is around $0.9^{\circ} \mathrm{C}$.

Table 2. Years of which breaks in the temperature series

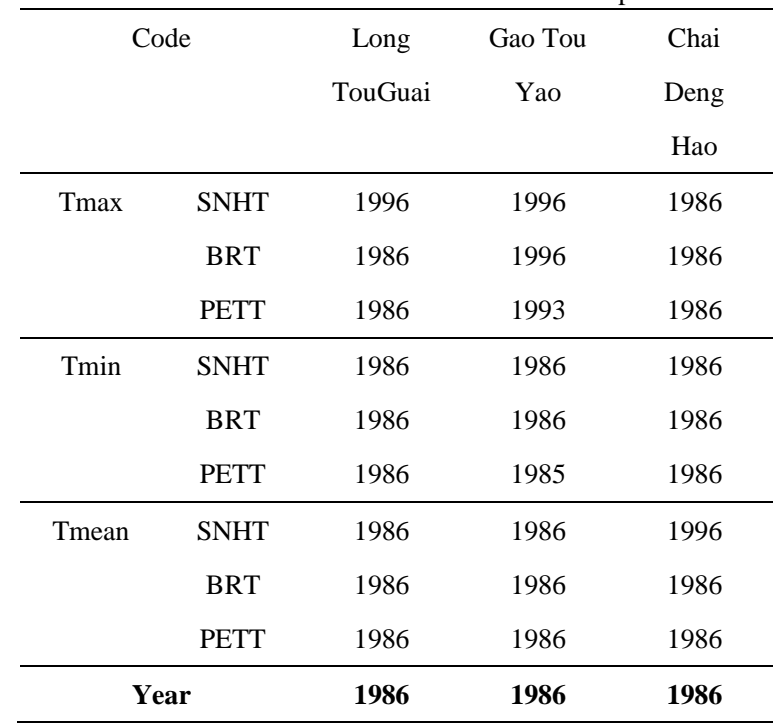

Fig 3 shows the application of the VNRT to the series of monthly residuals of Tmax ,Tmin and Tmean of the 3 stations. 
It is observed that the empirical statistics (thin solid and thick line respectively) depart from the $99 \%$ confidence level bands (dashed lines) around 1986. The nonrandomness of these series has to be accepted then with a probability of at least 99\%. Most point of intersection before 1980s in Tmax and Tmin, and it is obviously changed in the 2007 of Tmean in Chai DengHao station. Also, the nonrandomness of these series has to be accepted then with a probability of at least $99 \%$. Owing to the persistence of the departure of the statistic from the confidence bands, it cannot be discarded that the lack of randomness of the temperature series could be attributable to relevant time trends. This aspect is investigated in the next section.

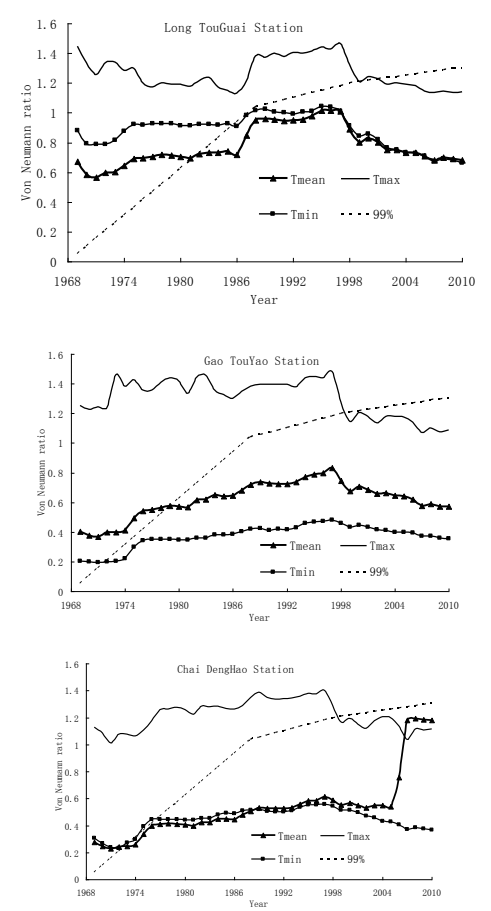

Fig 3. VNRT applied to monthly residual of

Tmax, Tmin and Tmean for 3 stations.

Dashed lines represent $99 \%$ confidence bands.

\section{TEMPERATURE TIME TRENDS}

Table 3 lists the number of calendar days with significant positive or negative trends of Tmax, Tmin and mDTR for these three stations. Almost all annual average temperature trends are positive of Tmax, Tmin in three station locations. For Tmax, Long TouGuai station has 20 days, Gao TouYao has 28 days and Chai DengHao has 54 days with significant positive trend. The time trend of Tmin is quite similar with Tmax, which appears significant positive trend. Positive trends exceed $0.9^{\circ} \mathrm{C} /$ decade, while negative trends are more moderate (mostly up to $-0.8^{\circ} \mathrm{C} /$ decade).

The results point then to a generalized increase in daily Tmax and Tmin. This increase is confirmed by the validation of the field significance in terms of the $M-K$ test. Three stations with positive time trends confirm the existence of a field positive trend for mDTR at $95 \%$ significance level.

Table 3. Number of calendar days with significant positive and negative time trends of different temperature ( $\alpha=0.95$ )

\begin{tabular}{ccccc}
\hline & Code & Long & Gao & Chai \\
& & TouGuai & Tou & Deng \\
& & & Yao & Hao \\
\hline \multirow{4}{*}{ Tmax } & Positive & 20 & 28 & 54 \\
& Negative & 1 & 1 & 0 \\
\hline \multirow{4}{*}{ Tmin } & Total & 21 & 29 & 54 \\
& Positive & 129 & 220 & 210 \\
& Negative & 0 & 0 & 0 \\
\hline \multirow{3}{*}{ Tmean } & Total & 129 & 220 & 210 \\
& Positive & 1 & 0 & 0 \\
& Negative & 69 & 149 & 80 \\
& Total & 70 & 149 & 80 \\
\hline
\end{tabular}

Fig 4 depicts the distribution of average daily time trends along the year. For every calendar day, the average trend is obtained by considering all stations having a significant local trend for that day. A first relevant feature is the clear predominance of days with positive average trend for daily Tmax. The most relevant period with negative Tmin trends is observed from November to March. Many peaks exceeding $1.5^{\circ} \mathrm{C} /$ decade appear along the year for Tmin. Positive temperature trends are in general slightly more moderate from May to November for Tmax. For mDTR, positive trends are whole distributed along the year, while a clear predominance of positive trends is observed in the April to June. A remarkable positive trend is also obtained for Tman in winter $\left(0.7^{\circ} \mathrm{C} /\right.$ decade $)$. The only average negative trend is detected in autumn for Tmin in winter $\left(-0.5^{\circ} \mathrm{C} /\right.$ decade $)$. mDTR clearly trends to increase at annual scale $\left(1.25^{\circ} \mathrm{C} /\right.$ decade $)$, in autumn $\left(-1.30^{\circ} \mathrm{C} /\right.$ decade $)$ and especially in summer $\left(-1.44^{\circ} \mathrm{C} /\right.$ decade $)$, while quite small changes are detected for the rest of seasons. 

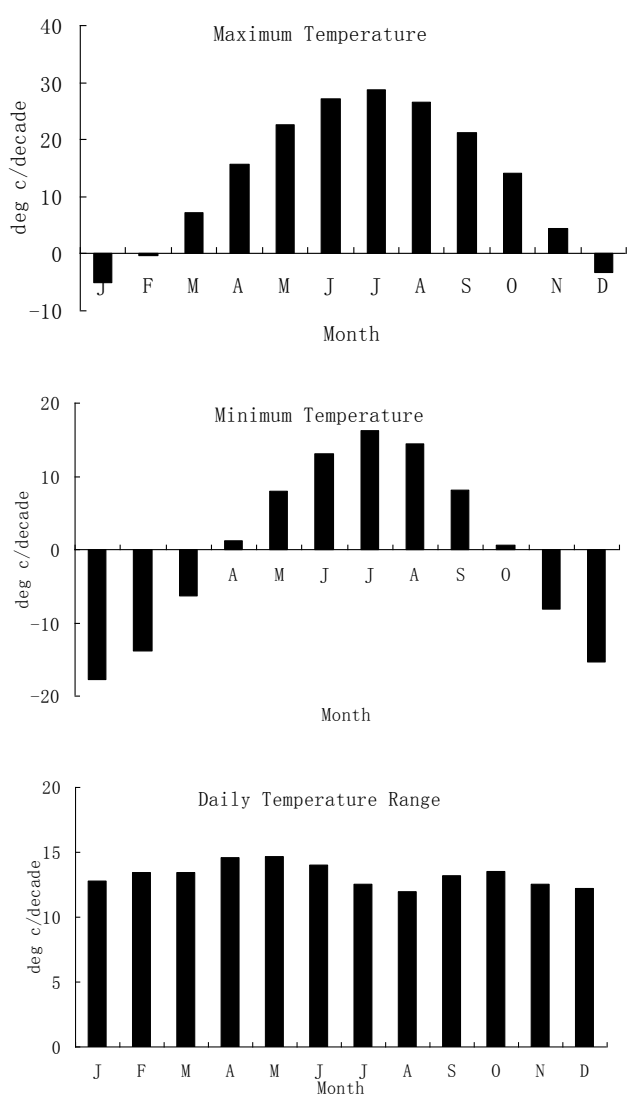

Fig 4. Time trends along the year for: daily Tmax, daily Tmin and mDTR

\section{CONCLUSION}

This study analyzed the Tmax, Tmin and mDTR temperature time in the XiLiuGou basin. Daily temperature was applied to the long term daily time series of 3 rainfall stations in the XiLiuGou basin. The results of the study led to the following conclusions:

1.Based on the daily temperature data form 1969 to 2010, researches analyzed the Tmax, Tmin and mDTR temperature time in the XiLiuGou basin (Ten-watershed in the middle of Yellow River). The empirical statistics departs from the $99 \%$ confidence level bands around different years, when most points of intersection are before 1980s in Tmax and Tmin.

2.The most relevant period with negative Tmin trends is observed from November to March. Most positive temperature trends are general slightly more moderate from May to November for Tmax.

\section{ACKNOWLEDGEMENTS}

This study was supported by Central public welfare research institutes basic scientific research business expenses special funds HKY-JBYW-2012-19 and National Technology Support Project No. 2012BAB02B0403. We also gratefully acknowledge the department of China Meteorological Data Sharing Service System. We also thankful to anonymous reviewer for his constructive comments in the manuscript review.

\section{REFERENCES}

[1] Rehman Shafiqur, Temperature and rainfall variation over Dhahran, Saudi Arabia, (1970-2006). International of climatology, DOI:10.1002/joc.1907,2009.

[2] M P Guo, G H Zhang, Yu Mao. The change of temperature in eastern Loess Plateau. Journal of Arid Land Resources and Environment,23(9):47-50, 2009.

[3] RA Wang. Response of maximum and minimum air temperature to climate warming in Pingliang gully region of Loess Plateau. Journal of Arid Land Resources and Environment, 24(6):72-75, 2010.

[4] Wijngaard JB, Klein Tank MG, K"onnen GP. Homogeneity of 20th century European daily temperature and precipitation series. International Journal of Climatology, 23: 679-692, 2003.

[5] Alexandersson H. A homogeneity test applied to precipitation data. Journal of Climatology, 6: 661-675, 1986.

[6] Buishand TA. Some methods for testing the homogeneity of rainfall records. Journal of Hydrology, 58: 11-27, 1982.

[7] Pettitt AN. A non-parametric approach to the change-point detection. Applied Statistics, 28: 126-135, 1979.

[8] Von Neumann J, Distribution of the ratio of the mean square successive difference to the variance. Annals of Mathematical Statistics,13:367-395,1941. 